\title{
Article \\ Acute Physiological Response to Different Sprint Training Protocols in Normobaric Hypoxia
}

\author{
Naomi Maldonado-Rodriguez ${ }^{1}$, David J. Bentley ${ }^{1,2}$ and Heather M. Logan-Sprenger ${ }^{1,2,3, * \text { (D) }}$ \\ 1 Faculty of Kinesiology \& Physical Education, University of Toronto, Toronto, ON M5S 1A4, Canada; \\ nmrod@mail.ubc.ca (N.M.-R.); bentley.dj@gmail.com (D.J.B.) \\ 2 Canadian Sport Institute of Ontario, Toronto, ON M1C 0C7, Canada \\ 3 Faculty of Health Sciences, Ontario Tech University, Oshawa, ON L1H 7K4, Canada \\ * Correspondence: heather.sprenger@ontariotechu.ca
}

check for

updates

Citation: Maldonado-Rodriguez, N.; Bentley, D.J.; Logan-Sprenger, H.M. Acute Physiological Response to Different Sprint Training Protocols in Normobaric Hypoxia. Int. J. Environ. Res. Public Health 2022, 19, 2607. https://doi.org/10.3390/ ijerph19052607

Academic Editors: Chansol Hurr and Jordan Patik

Received: 10 January 2022

Accepted: 21 February 2022

Published: 24 February 2022

Publisher's Note: MDPI stays neutral with regard to jurisdictional claims in published maps and institutional affiliations.

Copyright: (C) 2022 by the authors. Licensee MDPI, Basel, Switzerland. This article is an open access article distributed under the terms and conditions of the Creative Commons Attribution (CC BY) license (https:// creativecommons.org/licenses/by/ $4.0 /)$.

\begin{abstract}
Background: the purpose of this study was to examine acute physiological responses to and the performance effects of two sprint training protocols in normobaric hypoxic conditions. Methods: Healthy competitive female $(n=2)$ and male $(n=5)$ kayakers $(19 \pm 2.1$ years) performed four sprint training sessions on a kayak ergometer over a period of two weeks. Participants performed five sets of $12 \times 5$ s sprints or $3 \times 20 \mathrm{~s}$ sprints in both normobaric normoxic $\left(\mathrm{NOR}, \mathrm{F}_{\mathrm{i}} \mathrm{O}_{2}=20.9 \%\right.$ ) or normobaric hypoxic $\left(\mathrm{HYP}, \mathrm{F}_{\mathrm{i}} \mathrm{O}_{2}=13.6 \%\right.$ ) conditions. The peak power output (PPO), rate of perceived exertion (RPE), and heart rate (HR) of each participant were monitored continuously. Their blood lactate concentrations $\left(\left[\mathrm{BLa}^{+}\right]\right)$, in addition to their blood gas (mixed-venous partial pressure $(\mathrm{p})$ of carbon dioxide $\left(\mathrm{pCO}_{2}\right), \mathrm{O}_{2}\left(\mathrm{pO}_{2}\right)$, and oxygen saturations $\left.\left(\mathrm{sO}_{2}\right)\right)$ were collected before and after exercise. Results: A significantly greater $\mathrm{RPE}, \mathrm{HR}$, and $\left[\mathrm{BLa}^{+}\right]$response and a significant decrease in $\mathrm{pCO}_{2}, \mathrm{pO}_{2}$, and $\mathrm{sO}_{2}$ were observed in HYP conditions versus NOR ones, independent of the type of training session. The PPO of participants did not differ between sessions. Their RPE in HYP12 $\times 5$ was greater compared to all other sessions. Conclusions: The HYP conditions elicited significantly greater physiological strain compared to NOR conditions and this was similar in both training sessions. Our results suggest that either sprint training protocol in HYP conditions may induce more positive training adaptations compared to sprint training in NOR conditions.
\end{abstract}

Keywords: hypoxia; sprint training; physiological response

\section{Introduction}

Traditional "altitude training", where athletes live and train at real or simulated altitudes of 1800-2400 m, has focused on enhancing sea level endurance performance by improving red cell mass [1]. Live high train low (LHTL) models are commonly used in preseason training to enhance aerobic and potentially anaerobic performance $[2,3]$. LHTL training approaches require athletes to adhere to prolonged and consistent exposure ( $\geq 3$ weeks) to hypoxia, while training at sea level, in order to stimulate an increase in red blood cell (RBC) mass whilst reducing the potentially detrimental effects of continuous altitude exposure on detraining [4]. However, such training is neither time- nor cost-effective [5]. While the positive effects on aerobic capacity are well-documented, the reported effects on anaerobic performance have been equivocal.

Traditional LHTL protocols, designed to induce improvements in aerobic capacity, typically do not result in meaningful anaerobic improvements, most likely as a result of training design that does not sufficiently stress the anaerobic system [6,7]. Recently, intermittent hypoxia training (IHT), "a method where athletes live at or near sea level but train under hypoxic conditions", has been explored as a potential alternative to traditional training at altitude to stimulate adaptations that may affect anaerobic performance [7]. Studies have shown that sport-specific IHT may lead to speed/power performance improvements 
or repeated sprint ability via increased resting $\mathrm{pH}$, enhanced buffering capacity, and improved blood perfusion [7-15]. However, despite many potential physiological adaptations, IHT has failed to show consistent performance improvements, such as in relation to power output or performance in $10 \mathrm{~s}$ or $30 \mathrm{~s}$ all out tests $[13,16,17]$. One important consideration is that training must be performed at a maximal intensity in order to augment anaerobic performance $[5,7,15]$. One way of adapting IHT for anaerobic performance-specific adaptations may be sprint training in hypoxia [7]. The parameters of training design (e.g., modality, work-to-rest ratio, repetition duration) should be such that they result in incomplete recovery, so that they induce glycolytic adaptations. One such parameter, sprint duration, largely influences the relative contribution of aerobic and anaerobic energy systems. A duration of $30 \mathrm{~s}$ is conventionally used in sprint training, with the first 5-10 s representing the period during which peak power is achieved, with the latter 20-25 s constituting an effort to maintain this output [18]. Hazell and colleagues (2010), when comparing $10 \mathrm{~s}$ and $30 \mathrm{~s}$ sprint protocols, suggested that the initial generation of peak power output (PPO) was likely responsible for sprint interval training adaptations [19]. Sprint training is primarily dependent on the ability to match ATP resynthesis rate to utilization rate and altered intracellular and extracellular ion concentrations [12]. The added stimulus of hypoxia is likely to increase metabolic stress and, thus, hypothetically induce greater physiological adaptations and performance improvements.

The sport of flat water canoeing and kayaking encompasses events ranging between a 'sprint' $(200 \mathrm{~m})$ of $<30 \mathrm{~s}$ to events that are 1-2 $\mathrm{min}$ in duration $(1000 \mathrm{~m})$. It has been shown that there is a large aerobic component to these events, especially $1000 \mathrm{~m}$ events [20]. In contrast, in the sprint event, there is a heavy anaerobic component, with athletes requiring considerable upper body anaerobic capacity. Competitive canoe and kayak athletes undertake sprint training and other forms of anaerobic conditioning in their preparation [20].

The acute response to different durations of anaerobic work intervals, with respect to work volume and work-to-rest ratio, performed in hypoxia, has not been previously investigated, and this is especially true in the context of kayak athletes, for whom anaerobic training is an important sport-specific consideration. The purpose of this study was to examine acute physiological responses to two sprint training protocols (sets of $5 \mathrm{~s}$ versus $30 \mathrm{~s}$ ) in normobaric hypoxic conditions. We hypothesized that, (1) the hypoxic condition would induce greater physiological strain compared to normoxic conditions, and (2) longer duration sprints would result in a greater physiological response in terms of blood parameters.

\section{Materials and Methods}

Seven healthy well-trained male or female kayakers (female: $n=2$; male: $n=6$ ) aged 15-24 (mean \pm SD: $19 \pm 2.1$ years) were recruited from local canoe-kayak clubs (training $18 \pm 2 \mathrm{~h}$ per week). All kayakers competed at a national and international level as part of their respective provincial or national federations in flatwater kayaking. Participants were sea level natives with no exposure to hypoxia training. All participants were actively training athletes in their off-season. Prior to the initial training sessions, a risk assessment was completed to identify any potential confounding respiratory, neurological, musculoskeletal, or circulatory conditions that may have been deemed a risk to sprint training or training in hypoxia. Parents (assent was required) and participants were informed both verbally and in writing of the experimental protocol and potential risks before giving their verbal and written assent and consent, respectively, to participate. The Research Ethics Board at the Canadian Sport Institute Ontario approved the study (REB\#18-01).

\subsection{Experimental Procedure}

Athletes completed four sprint training sessions on a kayak ergometer (K1 Speed Stroke Ergometer, KayakPro, Miami Beach, FL, USA) over a period of 2 weeks, with a minimum of $48 \mathrm{~h}$ between each session. Each session occurred in an environmentally controlled chamber (K2 Room, Storex Ca Inc., Montreal, QC, Canada). In a single-blind 
fashion, each session was performed in the altitude chamber to ensure participants were blind to the environmental condition. The order of the training sessions was randomized to control for potential physiological adaptations that may have occurred throughout the duration of the testing. Previous studies have demonstrated that participants are not able to distinguish between hypoxia and normoxia during intermittent sprint training [7]. The trials were conducted at the same of time of the day. Any supplementary normoxic training that occurred outside the study was recorded (modality, duration, and intensity).

\subsection{Training Protocol}

Participants performed five sets of $12 \times 5$ s sprints (protocol 1) or $3 \times 20$ s sprints (protocol 2) in both normobaric normoxia (NOR, $0 \mathrm{~m}$ altitude, $\mathrm{F}_{\mathrm{i}} \mathrm{O}_{2}=20.9 \%$ ) and normobaric hypoxia (HYP, $3500 \mathrm{~m}$ altitude, $\mathrm{F}_{\mathrm{i}} \mathrm{O}_{2}=13.6 \%$ ) (see Supplementary Materials). The warm-up consisted of 5-min of light intensity paddling at a self-selected pace, followed by $4 \times 10 \mathrm{~s}$ preparatory 'submaximal efforts' with $20 \mathrm{~s}$ of light intensity work between each bout and 2 min of passive rest before the start of the sprint session ( $11 \mathrm{~min}$ total). Protocol 1 consisted of five sets of $12 \times 5 \mathrm{~s}$ sprints with $15 \mathrm{~s}$ of active recovery between each repetition and $2 \mathrm{~min}$ of passive rest between sets. Protocol 2 consisted of five sets of $3 \times 20 \mathrm{~s}$ sprints with $60 \mathrm{~s}$ active recovery between repetition and $2 \mathrm{~min}$ of passive rest between sets. Both protocols were matched for total work volume and work-to-rest ratio (1:3) based on recommendations set forth by Brocherie and colleagues (2017) [8]. The focus of the training was to maximize hypoxia exposure in order to improve anaerobic capacity by way of short high-intensity exercise, replicating the demands of kayaking. Athletes were asked to perform maximally for each sprint.

Training was completed in a normobaric hypoxic chamber that was purpose-built for intermittent hypoxia training (K2 Room, Storex Ca Inc., Montreal, QC, Canada). The chamber is a $5 \times 5 \mathrm{~m}$ room with an airlock and a glass wall for viewing access. The temperature and humidity were set at approximately $20{ }^{\circ} \mathrm{C}$ and $20 \%$, respectively, for consistency. Participants were monitored continuously using heart rate (HR) and rate of perceived exertion (RPE) [21]. Their peak HR was captured after every sprint using a Polar Strap (Polar H10, Polar Electro, Nassau, NY, USA) and recorded using the FIT IV Pulse application on an iPad (iPad version 3, Apple, Cupertino, CA, USA). Their RPE was recorded after every set on a scale of 6 to 20. Capillary blood samples for [BLa ${ }^{+}$, blood gas, and metabolite analysis were collected throughout. $\left[\mathrm{BLa}^{+}\right]$was collected pre-exercise, after set 3 , and post-exercise. Blood gas and metabolites were collected immediately pre- and post-exercise.

\subsection{Blood Sampling}

Blood samples $(5 \mathrm{uL})$ were collected from participants' fingertips and analyzed for blood lactate concentration $\left[\mathrm{BLa}^{+}\right]$using a portable hand-held blood lactate analyzer (Lactate PRO, USA) pre-exercise ( 5 min prior to start), after set 3 , and post-exercise ( $5 \mathrm{~min}$ post). Blood bicarbonate $\left(\mathrm{HCO}^{-}\right), \mathrm{pH}$, mixed-venous partial pressure of carbon dioxide $\left(\mathrm{pCO}_{2}\right)$, oxygen $\left(\mathrm{pO}_{2}\right)$, and oxygen saturation $\left(\mathrm{sO}_{2}\right)$ were measured via capillary analysis using a blood gas analyzer (ABL80, Radiometer, Mississauga, ON, Canada). Various metabolites, including sodium $\left(\mathrm{Na}^{+}\right)$, potassium $\left(\mathrm{K}^{+}\right)$, calcium $\left(\mathrm{Ca}^{2+}\right)$, and chloride $\left(\mathrm{Cl}^{-}\right)$, were also assessed using a $125 \mathrm{uL}$ plastic capillary tube with 70iu balanced heparin pre- and post-exercise and measured using a blood gas analyzer (ABL80, Radiometer, Mississauga, $\mathrm{ON}$, Canada). All resting blood samples were taken in normoxia while the post-exercise blood draw was collected in either HYP or NOR conditions depending on the exercise session.

\subsection{Performance Measures}

The participant's peak power output (PPO) for each sprint was recorded using the kayak ergometer's integrated monitor. The PPO was then averaged per set and per session and normalized to body mass $(\mathrm{W} / \mathrm{kg})$. 


\subsection{Statistical Analysis}

Data are mean \pm standard deviation (SD), unless otherwise stated. Changes in the mean and standard deviation of the variables representing between- and within-subject variability were assessed using a two-way repeated-measures ANOVA in SPSS (Version 24, IBM Corp., Armonk, NY, USA). RPE and peak HR were averaged to a session mean for all four trials. The difference between pre- and post-exercise values for [BLa+], blood gas, and metabolites was calculated to obtain a mean change over time, thus removing the third factor of time. Only mean values in PPO were compared using a three-way ANOVA with repeated measures model. Post-hoc analyses were conducted where applicable and adjusted for multiple comparisons using Bonferroni correction. Both $\mathrm{HR}$ and $\mathrm{sO}_{2}$ were not normally distributed; as both did not respond to transformation, data analysis was run with and without outliers (one in each). As they did not change, results from analysis with outliers are reported. To supplement important findings, effect sizes $\left(\eta^{2}\right)$ were calculated as the ratio of the mean difference to the pooled SD of the difference. The magnitude of the effect size was classed as trivial $(<0.2)$, small $(0.2-0.6)$, moderate $(0.6-1.2)$, large (1.2-2.0), and very large (>2.0) based on previous published guidelines [22]. Moreover, exact $p$ values and Cohen $d$ are presented to show the magnitude of effect.

\section{Results}

The mean \pm SD values are outlined in Table 1 . The PPO of participants did not differ between training protocols (Table 1). All participants trained at a very high intensity, with mean session RPEs ranging from 15 to 17 (Table 1). A significant interaction was found between the environmental condition and training protocol with respect to RPE ( $p=0.011$, $\eta^{2}=0.76$ ). Post-hoc analyses revealed that participants reported a significantly greater RPE after the HYP12 $\times 5$ protocol, compared to the NOR12 $\times 5$ protocol $(p=0.003)$. In addition, we found a significant interaction in terms of peak HR between training protocols $(12 \times 5 \mathrm{vs}$. $3 \times 20$ ) and environmental conditions (normoxia vs. hypoxia) (Table $1, p=0.014, \eta^{2}=0.73$ ). Peak HR in both HYP12 $\times 5$ and HYP3 $\times 20$ was greater than its normoxia counterpart, with $p=0.029$ and $p=0.025$ respectively. Peak HR in NOR3 $\times 20$ was significantly greater than in NOR12 $\times 5(p=0.003)$. There were no differences in terms of hypoxia between training protocols.

Post-exercise $\left[\mathrm{BLa}^{+}\right]$values were elevated in all training protocols, compared to preexercise resting values (refer to Table 1 ). Mean $\left[\mathrm{BLa}^{+}\right]$values were above the lactate threshold, which is generally defined as between $4 \mathrm{mmol} / \mathrm{L}$ [20]. Post-exercise [BLa $\left.{ }^{+}\right]$ levels were significantly greater in hypoxia, compared to normoxia $\left(p=0.029, \eta^{2}=0.65\right)$, regardless of the training session $(12 \times 5$ or $3 \times 20)$ (Table 1$)$. Additionally, post-exercise $\left[\mathrm{BLa}^{+}\right]$levels were significantly greater following the $3 \times 20$ protocol, compared to the $12 \times 5$ protocol, regardless of the environmental condition $\left(p=0.016, \eta^{2}=0.72\right)$.

No significant differences were observed in $\mathrm{pH}$ between conditions or sprint sessions $(p>0.05)$. However, we did note an interaction that trended towards significance $(p=0.085)$. For both the $3 \times 20$ sprint sessions (HYP and NOR), $\mathrm{pH}$ fell below 7.35, suggesting that the $3 \times 20$ sprint session elicited metabolic acidosis in both HYP and NOR environmental conditions. Post-exercise $\mathrm{pCO}_{2}$ was significantly greater than pre-exercise values in the hypoxia conditions only $\left(p=0.05, \eta^{2}=0.57\right)$, independent of the training session (Figure 1A,B). On the other hand, post-exercise $\mathrm{pO}_{2}$ was significantly reduced in the hypoxia session $\left(p=0.001, \eta^{2}=0.91\right)$, irrespective of the training session (Figure $1 C, D$ ). There was no interaction between training protocol and environmental condition in either blood gases. Additionally, $\mathrm{sO}_{2}$ was significantly lower in hypoxia than in normoxia, independent of the training protocol $\left(p=0.001, \eta^{2}=0.9\right.$, Figure $\left.1 \mathrm{E}, \mathrm{F}\right)$. The training protocol $(12 \times 5$ or $3 \times 20)$ had no statistical effect on $\mathrm{pCO}_{2}$ or $\mathrm{pO}_{2}$ response. Lastly, we found no significant changes in the blood metabolites measured $\left(\mathrm{Na}^{+}, \mathrm{K}^{+}, \mathrm{Ca}^{2+}, \mathrm{Cl}^{-}, \mathrm{HCO}_{3}{ }^{-}\right)$. While it did not reach significance, $\mathrm{HCO}_{3}{ }^{-}$showed a trending decrease $\left(p=0.067, \eta^{2}=0.52\right)$ in the NOR3 $\times 20$ and both hypoxia sessions. 
Table 1. Mean performance and physiological measures pre- and post-training.

\begin{tabular}{|c|c|c|c|c|c|}
\hline & & \multicolumn{2}{|c|}{$12 \times 5$ Protocol } & \multicolumn{2}{|c|}{$3 \times 20$ Protocol } \\
\hline & & NOR & HYP & NOR & HYP \\
\hline $\mathrm{PPO}(\mathrm{W} / \mathrm{kg})$ & & $3.87 \pm 1.04$ & $3.84 \pm 0.89$ & $3.56 \pm 0.32$ & $4.14 \pm 1.4$ \\
\hline RPE & & $15 \pm 1.21$ & $17 \pm 0.89 *$ & $16 \pm 0.73$ & $16 \pm 1.35$ \\
\hline Peak HR (bpm) & & $159 \pm 11^{\wedge}$ & $167 \pm 10 *$ & $164 \pm 8$ & $170 \pm 11^{*}$ \\
\hline$\left[\mathrm{BLa}^{+}\right](\mathrm{mmol} / \mathrm{L})$ & $\begin{array}{l}\text { Pre } \\
\text { Post }\end{array}$ & $\begin{array}{c}1.18 \pm 0.2 \\
4.23 \pm 1.74\end{array}$ & $\begin{array}{c}1.9 \pm 0.57 \\
8.52 \pm 2.5 *\end{array}$ & $\begin{array}{c}1.64 \pm 0.6 \\
9.02 \pm 3.8^{\wedge}\end{array}$ & $\begin{array}{c}1.44 \pm 0.48 \\
10.28 \pm 3.0^{*}\end{array}$ \\
\hline \multicolumn{6}{|c|}{ Blood Gas/Metabolites } \\
\hline $\mathrm{pH}$ & $\begin{array}{l}\text { Pre } \\
\text { Post }\end{array}$ & $\begin{array}{l}7.41 \pm 0.042 \\
7.39 \pm 0.051 \\
\end{array}$ & $\begin{array}{l}7.41 \pm 0.013 \\
7.36 \pm 0.037\end{array}$ & $\begin{array}{l}7.43 \pm 0.031 \\
7.31 \pm 0.010 \\
\end{array}$ & $\begin{array}{l}7.42 \pm 0.035 \\
7.34 \pm 0.072 \\
\end{array}$ \\
\hline $\mathrm{pCO}_{2}(\mathrm{mmHg})$ & $\begin{array}{l}\text { Pre } \\
\text { Post }\end{array}$ & $\begin{array}{l}36.33 \pm 2.66 \\
33.67 \pm 3.33 \\
\end{array}$ & $\begin{array}{l}37.00 \pm 2.92 \\
25.8 \pm 4.44^{*}\end{array}$ & $\begin{array}{l}37.00 \pm 3.10 \\
29.00 \pm 3.39\end{array}$ & $\begin{array}{c}38.33 \pm 4.32 \\
29.33 \pm 2.34 \text { * } \\
\end{array}$ \\
\hline $\mathrm{pO}_{2}(\mathrm{mmHg})$ & $\begin{array}{l}\text { Pre } \\
\text { Post }\end{array}$ & $\begin{array}{l}76.33 \pm 14.26 \\
80.33 \pm 16.75 \\
\end{array}$ & $\begin{array}{c}75.4 \pm 9.26 \\
57.8 \pm 5.45^{*}\end{array}$ & $\begin{array}{c}65.8 \pm 5.17 \\
90.80 \pm 11.26\end{array}$ & $\begin{array}{c}69.17 \pm 9.79 \\
57.17 \pm 14.74 \text { * }\end{array}$ \\
\hline $\mathrm{HCO}_{3}{ }^{-}(\mathrm{mEq} / \mathrm{L})$ & $\begin{array}{l}\text { Pre } \\
\text { Post }\end{array}$ & $\begin{array}{c}22.6 \pm 2.90 \\
19.98 \pm 2.69\end{array}$ & $\begin{array}{l}23.20 \pm 1.63 \\
14.18 \pm 2.30\end{array}$ & $\begin{array}{c}24.38 \pm 1.95 \\
14.6 \pm 4.81\end{array}$ & $\begin{array}{c}24.25 \pm 1.71 \\
15.7 \pm 3.14\end{array}$ \\
\hline $\mathrm{sO}_{2}(\%)$ & $\begin{array}{l}\text { Pre } \\
\text { Post }\end{array}$ & $\begin{array}{c}95.8 \pm 3.6 \\
96.07 \pm 3.7\end{array}$ & $\begin{array}{l}94.25 \pm 5.75 \\
89.2 \pm 2.52 *\end{array}$ & $\begin{array}{l}95.28 \pm 1.9 \\
97.43 \pm 1.0\end{array}$ & $\begin{array}{l}95.28 \pm 2.84 \\
87.97 \pm 5.6^{*}\end{array}$ \\
\hline
\end{tabular}

Data are mean \pm SD. NOR, normobaric normoxia $\left(20.9 \% \mathrm{O}_{2}\right)$; HYP, normobaric hypoxia $\left(13.6 \% \mathrm{O}_{2}\right)$; PPO, peak power output; $\mathrm{W} / \mathrm{kg}$, watts per kilogram body mass; $\mathrm{HR}$, heart rate; $\mathrm{bpm}$, beats per minute; $\left[\mathrm{BLa}^{+}\right]$, blood lactate concentration; $\mathrm{pCO}_{2}$, partial pressure of carbon dioxide; $\mathrm{pO}_{2}$, partial pressure of oxygen; $\mathrm{HCO}_{3}{ }^{-}$, bicarbonate $\mathrm{sO}_{2}$, saturation of oxygen. * Significant difference between the normoxic and hypoxic response within the training protocol $(p<0.05) ;{ }^{\wedge}$ Significant difference between training protocols $(p<0.05)$.
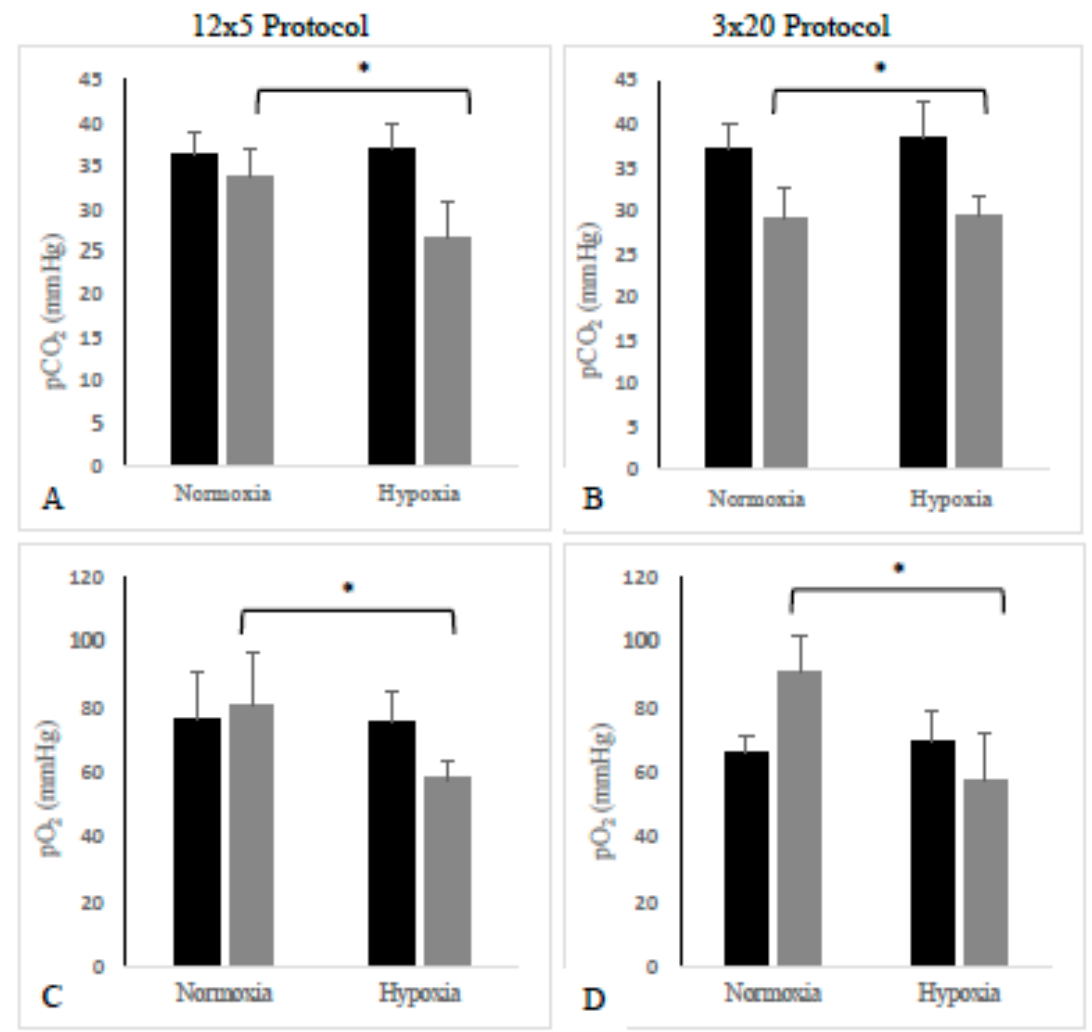

Figure 1. Cont. 


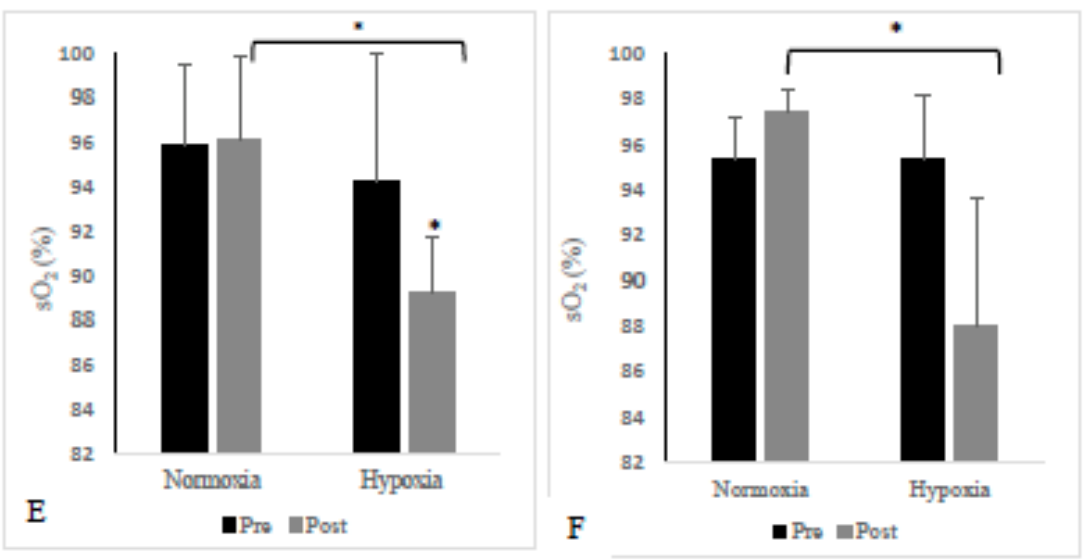

Figure 1. Mean pre- and post-exercise blood gas measurements for the two sprint training protocols $(12 \times 5$ versus $3 \times 20)$. $(\mathbf{A})$ partial pressure of carbon dioxide $\left(\mathrm{pCO}_{2}\right)$ in the $12 \times 5$ protocol; $(\mathbf{B})$ partial pressure of carbon dioxide $\left(\mathrm{pCO}_{2}\right)$ in the $3 \times 20$ protocol; $(\mathbf{C})$ partial pressure of oxygen $\left(\mathrm{pO}_{2}\right)$ in the $12 \times 5$ protocol; (D) partial pressure of oxygen $\left(\mathrm{pO}_{2}\right)$ in the $3 \times 20$ protocol; $(\mathrm{E})$ blood oxygen saturation $\left(\mathrm{sO}_{2}\right)$ in the $12 \times 5$ protocol; $(\mathbf{F})$ blood oxygen saturation $\left(\mathrm{sO}_{2}\right)$ in the $3 \times 20$ protocol. Data are mean \pm SD. * Significant difference versus normoxia, independent of training protocol $(p<0.05)$.

\section{Discussion}

The results of this study demonstrate that regardless of the sprint training stimulus $(12 \times 5$ vs. $3 \times 20)$, a controlled normobaric hypoxic environment of $13.6 \% \mathrm{O}_{2}$ elicited significantly greater acute responses in terms of RPE, $\mathrm{HR}, \mathrm{BLa}$ concentration, and $\mathrm{pCO}_{2}$, with significantly lower post-exercise $\mathrm{pO}_{2}$ and $\mathrm{sO}_{2}$, along with a trend of lower blood $\mathrm{pH}$ and $\mathrm{HCO}^{-}$, compared to a sprint training session in normobaric normoxic conditions. When comparing the sprint training session stimulus $(12 \times 5$ vs. $3 \times 20)$, the results show that the RPE of the participants was higher in the $12 \times 5$ sprint workout; however, their $\mathrm{HR}$ and $\mathrm{BLa}^{+}$concentrations were significantly greater in the $3 \times 20$ sprint workout, with no difference between the sprint training stimulus in terms of blood gases, $\mathrm{pH}$, or blood metabolites.

\subsection{Peak Power Output during Sprint Training in Hypoxia and Normoxia}

Athletes were able to maintain their PPO, independent of the training session. This is congruent with the literature, which suggests that PPO is generated during the first $5-10 \mathrm{~s}$ of exertion $[19,23]$. Thus, athletes would have had time to reach their maximal power output even during the short-duration sprint protocol. An athlete's ability to generate power throughout a session is an important consideration when it comes to potential adaptations to the anaerobic system. It is well-documented that athletes must train at maximal intensities in order to induce improvement in anaerobic capacity, likely due to enhanced glycolytic activity in muscles via increased mRNA expression related to $\mathrm{pH}$ regulation, upregulation of anaerobic metabolism, increased buffering capacity, modified fast twitch (FT) fiber behavior, and increased end-product metabolite removal mechanisms $[5,7,8,13-15,24,25]$. In contrast, a reduction in PPO may have indicated that the training stimulus was too high. This has historically been an issue in this field of research, where prolonged exposure to hypoxia leads to a reduction in training quality and intensity, which may explain the lack of performance improvements previously noted, despite physiological adaptations [26-28]. It is thus paramount that athletes work maximally. Our results demonstrate that the sprint prescription $(12 \times 5$ or $3 \times 20)$ did not impair repeated maximal power output over a single session. The question becomes whether the repeated maximal power output can be sustained over multiple sessions to elicit positive training adaptations. 


\subsection{Physiological Responses to Sprint Training in Hypoxia and Normoxia}

Peak HR was greater in hypoxia than normoxia, independent of the training session. As expected, the reduction in the fraction of inspired oxygen $\left(\mathrm{F}_{\mathrm{i}} \mathrm{O}_{2}=13.6 \%\right)$ resulted in greater cardiovascular strain, which translated into an increase in HR. Moreover, peak HR in NOR3 $\times 20$ was greater than in NOR12 $\times 5$. Additionally, athletes rated the intensity of the exercise as very high. Only HYP12 $\times 5$ resulted in a greater RPE compared to its normoxia counterpart, but this was not reflected in any PPO differences. Interestingly, no differences were noted between NOR3 $\times 20$ and HYP3 $\times 20$. Studies have reported that shorter sprint durations see a greater relative contribution from the anaerobic system [29]. Thus, a $5 \mathrm{~s}$ sprint would be a greater stressor on the anaerobic system compared to a $20 \mathrm{~s}$ sprint. This trend is also seen in $\left[\mathrm{BLa}^{+}\right]$, which was greater in HYP12 $\times 5$ than in NOR12 $\times 5$. Post-exercise $[\mathrm{BLa}+]$ values were greater than pre-exercise values, regardless of the training session. These results are not surprising, as the athletes were instructed to sprint maximally. A high lactate accumulation is consistent with the literature, which has shown that high intensity short duration exercise, such as sprint training, leads to [BLa ${ }^{+}$] accumulation above the lactate threshold (typically defined as $4 \mathrm{mmol} / \mathrm{L}$ ). Elevated lactate levels at the cessation of exercise is indicative of anaerobic metabolism [30]. Additionally, $\left[\mathrm{BLa}^{+}\right]$was higher in HYP12 $\times 5$ compared to NOR12 $\times 5$, but no differences were noted between NOR3 $\times 20$ and HYP3 $\times 20$. This appears to be the only physiological response that supports our RPE findings. Much of our data suggests that the acute physiological response to HYP12 $\times 5$ and HYP3 $\times 20$ was similar. It is possible that the increase in $[\mathrm{BLa}+]$ resulted in greater muscular discomfort and, consequently, an increase in RPE and $[\mathrm{BLa}+][31,32]$.

\subsection{Blood Gas Responses to Sprint Training in Hypoxia and Normoxia}

A significant decrease in $\mathrm{pCO}_{2}$ and $\mathrm{pO}_{2}$ was observed in the hypoxic conditions. However, this response did not differ between the training protocols. A decrease in $\mathrm{pCO}_{2}$ is in accordance with a left shift of the oxyhemoglobin curve, which is typically observed following acute exposure to hypoxia [33]. The increase in ventilation, and, resulting respiratory alkalosis, are the body's attempt to increase $\mathrm{O}_{2}$ saturation in an environment with reduced oxygen availability. This reduction in $\mathrm{pCO}_{2}$ may also reflect increased buffering activity, whereby, in an attempt to maintain a stable $\mathrm{pH}$, the body will employ various mechanisms to buffer and maintain its acid-base balance. However, given the fact that $\mathrm{HCO}_{3}{ }^{-}$did not decrease significantly, ventilation may have played a greater role in the $\mathrm{pCO}_{2}$ response. Nonetheless, it is more likely that both contributed to this response. On the other hand, a decrease in mixed-venous $\mathrm{pO}_{2}$ is a typical response to high-intensity exercise, as oxygen consumption increases at the tissue level. The magnitude of this response is likely a reflection of hypoxic conditions. It is also important to note that in normoxia, the mean post-exercise $\mathrm{O}_{2}$ values increased (non-significantly) compared to pre-exercise. Elevated $\mathrm{pO}_{2}$ levels following exercise are indicative of hyperventilation and are congruent with our $\mathrm{pCO}_{2}$ results [25]. The reason why $\mathrm{pO}_{2}$ decreased in hypoxia is unclear and may be related to the magnitude of the hypoxic stimulus delivered [34]. Similarly, $\mathrm{sO}_{2}$ significantly decreased in hypoxia compared to normoxia, independent of the training session. This supports the literature, which has established that $\mathrm{sO}_{2}$ decreases acutely in hypoxia, reflecting the lower $\mathrm{F}_{\mathrm{i}} \mathrm{O}_{2}$ and the increase in oxygen extraction during exercise [14,25].

While $\mathrm{pH}$ did not reach statistical significance, the mean post-exercise values suggest that metabolic acidosis $(\mathrm{pH}<7.35)$ was present or very close in three of the training protocols $(\mathrm{HYP} 12 \times 5, \mathrm{NOR} 3 \times 20$, and HYP3 $\times 20)$ but not in NOR12 $\times 5(\mathrm{pH}=7.39)$ [35] This is possibly a result of the body's inability to eliminate or buffer waste metabolites or $[\mathrm{BLa}+]$, thereby leading to the accumulation of the measured metabolites and a decrease in $\mathrm{pH}$ [36]. Given the fact that one important adaptation induced from training in hypoxia is an increase in resting $\mathrm{pH}$, it is possible that this acute response may indicate that this protocol provided an adequate stressor to stimulate changes. These results clearly demonstrate that 
sprint training in hypoxia resulted in greater physiological strain compared to normoxia, with no differences seen between the training protocols.

\subsection{Perceptual Response to Sprint Training in Hypoxia and Normoxia}

It is well-documented that many anaerobic performance improvements, such as speed or power development, are mediated via adaptations in the neuromuscular system by way of motor unit recruitment, activation, and firing [37-40]. Studies show that maximal effort sprints require high levels of motor unit activation [40,41]. In this study, participants perceived the HYP12 $\times 5$ session to be harder than the three other sessions, despite them resulting in a similar PPO. One potential reason for this may be that the greater repetition of sprints in this session produced a greater stressor on the neuromuscular system due to rapid acceleration and deceleration. There is evidence that neural fatigue may be caused by a decrease in reflex sensitivity, which has been associated with force production and propulsion [18,42]. Bowtell and colleagues (2014) noted significantly reduced iEMG activity and running speed following sprint training in hypoxia [14]. These changes in neuromuscular activity may reflect fatigue development, possibly due to reduced central neural drive or impaired neuromuscular transmission [14,43]. Moreover, metabolic changes in the muscle, such as the [BLa+] accumulation and the decrease in pH seen in this study, may have accelerated the onset of muscle fatigue [40]. It is worth noting that in severely hypoxic conditions, neural fatigue may be a limiting factor and prevent athletes from training at the maximal intensities needed to obtain performance increments [3,44]. As such, the interaction between training protocol and altitude should be carefully considered when designing a program to achieve a stimulus great enough to induce adaptations but that does not impair performance.

\subsection{Limitations}

This study included a relatively small sample size, which may partly explain why certain effects were observed and others were not. Additionally, the results may have been affected by the range of competition levels tested. Participants ranged from national level to internationally ranked athletes. However, research shows that elite and sub-elite athletes often have different strengths and anaerobic power profiles $[45,46]$. Therefore, testing a sample of athletes of mixed competition levels may have confounded the results, especially given the small sample size. Moreover, although an effort was made to standardize the encouragement given, it is possible that the encouragement provided varied between athletes and may have affected the PPO results [47]. We also did not control the athlete's training outside of the four sessions. We asked athletes to record the modality, intensity, and duration of their training and maintain their training schedules consistently throughout the study. However, adherence to instructions is not always high and it is possible that supplementary training affected the athlete's ability to perform maximally.

\subsection{Future Directions and Practical Application}

Ultimately, our results suggest that sprint training in hypoxia elicits a greater physiological response compared to training in normoxic conditions, irrespective of the training protocol. However, athletes found HYP12 $\times 5$ more difficult, despite recording similar physiological responses to other sessions. Understanding the reasons why athletes' perceived rate of exertion was higher in this training protocol, while eliciting a similar physiological response, has important implications for training prescription. Special care should be taken when selecting a protocol that is applicable to the sport in question (i.e., which considers the demands of the sport) and one that considers the contribution of metabolic systems. Lastly, given the cross-sectional design of this study, we are only able to comment on acute physiological responses. Future research should explore the physiological response and adaptation to different training protocols in hypoxia using a longitudinal study design. 


\section{Conclusions}

The results of this study indicate that many of the acute responses seen were associated with the environmental conditions. Overall, the hypoxic conditions were physiologically more stressful than the normoxic conditions, irrespective of the training protocol, which is in keeping with our hypothesis. The significant changes observed in RPE, $[\mathrm{BLa}+], \mathrm{pCO}_{2}$, $\mathrm{pO}_{2}$, and $\mathrm{sO}_{2}$, as well as the non-significant but potentially meaningful changes seen in $\mathrm{pH}$ and $\mathrm{HCO}_{3}{ }^{-}$, indicate that the hypoxia sessions were more physiologically stressful for the athletes. It does not appear that the type of training influenced performance or physiological response, except in the case of [BLa+].

Supplementary Materials: The following supporting information can be downloaded at: https: / / www.mdpi.com/article/10.3390/ijerph19052607/s1, Figure S1: Study Timeline.

Author Contributions: All authors contributed to this study. Conceptualization: N.M.-R., D.J.B. and H.M.L.-S.; methodology: N.M.-R. and D.J.B.; data collection: N.M.-R.; writing-original draft preparation: N.M.-R.; writing-reviewing and editing: N.M.-R., D.J.B. and H.M.L.-S.; supervision: D.J.B. and H.M.L.-S. All authors have read and agreed to the published version of the manuscript.

Funding: This research received no external funding.

Institutional Review Board Statement: The Research Ethics Board at the Canadian Sport Institute Ontario approved the study (REB\#18-01).

Informed Consent Statement: Parents (assent was required) and participants were informed both verbally and in writing of the experimental protocol and potential risks before giving their verbal and written assent and consent, respectively, to participate. Written informed consent has been provided by all participants to publish this paper.

Data Availability Statement: The data presented in this study are available on request from the corresponding author. The data are not publicly available due to privacy restrictions.

Acknowledgments: We would like to thank the University of Toronto, Faculty of Kinesiology and Physical Education and the Canadian Sport Institute of Ontario (CSIO) for their support.

Conflicts of Interest: The authors declare no conflict of interest.

\section{References}

1. Böning, D. Altitude and Hypoxia Training-A Short Review. Int. J. Sports Med. 1997, 18, 565-570. [CrossRef] [PubMed]

2. Wehrlin, J.P.; Zuest, P.; Hallén, J.; Marti, B. Live high-train low for 24 days increases hemoglobin mass and red cell volume in elite endurance athletes. J. Appl. Physiol. 2006, 100, 1938-1945. [CrossRef] [PubMed]

3. Levine, B.D.; Stray-Gundersen, J. "Living high-training low": Effect of moderate-altitude acclimatization with low-altitude training on performance. J. Appl. Physiol. 1997, 83, 102-112. [CrossRef] [PubMed]

4. Kraemer, W.J.; Rogol, A.D. The Endocrine System in Sports and Exercise; John Wiley \& Sons: Hoboken, NJ, USA, 2008 ; Volume 11.

5. McLean, B.D.; Gore, C.J.; Kemp, J. Application of "live low-train high" for enhancing normoxic exercise performance in team sport athletes. Sports Med. 2014, 44, 1275-1287. [CrossRef]

6. Roberts, A.; Clark, S.; Townsend, N.; Anderson, M.; Gore, C.; Hahn, A. Changes in performance, maximal oxygen uptake and maximal accumulated oxygen deficit after 5, 10 and 15 days of live high:train low altitude exposure. Eur. J. Appl. Physiol. 2003, 88, 390-395. [CrossRef]

7. Faiss, R.; Girard, O.; Millet, G.P. Advancing hypoxic training in team sports: From intermittent hypoxic training to repeated sprint training in hypoxia. Br. J. Sports Med. 2013, 47 (Suppl. S1), i45-i50. [CrossRef]

8. Brocherie, F.; Girard, O.; Faiss, R.; Millet, G.P. Effects of Repeated-Sprint Training in Hypoxia on Sea-Level Performance: A Meta-Analysis. Sport Med. 2017, 47, 1651-1660. [CrossRef]

9. Nummela, A.; Rusko, H. Acclimatization to altitude and normoxic training improve 400-m running performance at sea level. J. Sports Sci. 2010, 18, 411-419. [CrossRef]

10. Czuba, M.; Wilk, R.; Karpiński, J.; Chalimoniuk, M.; Zajac, A.; Zef Langfort, J. Intermittent hypoxic training improves anaerobic performance in competitive swimmers when implemented into a direct competition mesocycle. PLoS ONE 2017, 12, 1-17. [CrossRef]

11. Bonetti, D.L.; Hopkins, W.G.; Kilding, A.E. High-intensity kayak performance after adaptation to intermittent hypoxia. Int. J. Sports Physiol. Perform. 2006, 1, 246-260. [CrossRef]

12. Galvin, H.M.; Cooke, K.; Sumners, D.P.; Mileva, K.N.; Bowtell, J.L. Repeated sprint training in normobaric hypoxia. Br. J. Sports Med. 2013, 47 (Suppl. S1), i74-i79. [CrossRef] [PubMed] 
13. Faiss, R.; Léger, B.; Vesin, J.M.; Fournier, P.E.; Eggel, Y.; Dériaz, O.; Millet, G.P. Significant Molecular and Systemic Adaptations after Repeated Sprint Training in Hypoxia. PLoS ONE 2013, 8, e56522. [CrossRef] [PubMed]

14. Bowtell, J.L.; Cooke, K.; Turner, R.; Mileva, K.N.; Sumners, D.P. Acute physiological and performance responses to repeated sprints in varying degrees of hypoxia. J. Sci. Med. Sport 2014, 17, 399-403. [CrossRef] [PubMed]

15. Iaia, F.M.; Bangsbo, J. Speed endurance training is a powerful stimulus for physiological adaptations and performance improvements of athletes. Scand. J. Med. Sci. Sport 2010, 20 (Suppl. S2), 11-23. [CrossRef]

16. Gore, C.J.; Hahn, A.G.; Aughey, R.J.; Martin, D.T.; Ashenden, M.J.; Clark, S.A.; Garnham, A.P.; Roberts, A.D.; Slater, G.J.; McKenna, M.J. Live high:train low increases muscle buffer capacity and submaximal cycling efficiency. Acta Physiol. Scand. 2001, 173, 275-286. [CrossRef]

17. Kasai, N.; Mizuno, S.; Ishimoto, S.; Sakamoto, E.; Maruta, M.; Goto, K. Effect of trianing in hypoxia on repeated sprint performance in female athletes. Springerplus 2015, 4, 310-317. [CrossRef]

18. Ross, A.; Leveritt, M. Long-Term Metabolic and Skeletal Muscle Adaptations to Short-Sprint Training. Sport Med. 2001, 31, 1063-1082. [CrossRef]

19. Hazell, T.J.; MacPherson, R.E.K.; Gravelle, B.M.R.; Lemon, P.W.R. 10 or 30-S Sprint Interval Training Bouts Enhance both Aerobic and Anaerobic Performance. Eur. J. Appl. Physiol. 2010, 110, 153-160. [CrossRef]

20. Micheal, J.S.; Rooney, K.B.; Smith, R.M. The metabolic demands of kayaking: A review. J. Sports Sci. Med. $2008,7,1-7$.

21. Borg, G.A. Psychophysical bases of perceived exertion. Med. Sci. Sports Exerc. 1982, 14, 377-381. [CrossRef]

22. Batterham, A.; Hopkins, W.G. Making meaningful inferences about magnitudes. Int. J. Sports Physiol. Perform. 2006, 1, 50-57. [CrossRef] [PubMed]

23. Heck, H.; Mader, A.; Hess, G.; Mücke, S.; Müller, R.; Hollmann, W. Justification of the 4-mmol/L Lactate Threshold. Int. J. Sports Med. 1985, 6, 117-130. [CrossRef] [PubMed]

24. Bogdanis, G.C.; Nevill, M.E.; Lakomy, H.K.A.; Boobis, L.H. Power output and muscle metabolism during and following recovery from 10 and $20 \mathrm{~s}$ of maximal sprint exercise in humans. Acta Physiol. Scand. 1998, 163, 261-272. [CrossRef] [PubMed]

25. Puype, J.; Van Proeyen, K.; Raymackers, J.M.; Deldicque, L.; Hespel, P. Sprint interval training in hypoxia stimulates glycolytic enzyme activity. Med. Sci. Sports Exerc. 2013, 45, 2166-2174. [CrossRef] [PubMed]

26. Geiser, J.; Vogt, M.; Billeter, R.; Zuleger, C.; Belforti, F.; Hoppeler, H. Training High—Living Low: Changes of Aerobic Performance and Muscle Structure with Training at Simulated Altitude. Int. J. Sports Med. 2001, 22, 579-585. [CrossRef]

27. Fulco, C.S.; Rock, P.B.; Cymerman, A. Maximal and submaximal exercise performance at altitude. Aviat. Space Environ. Med. 1998, 69, 793-801. Available online: http:/ /www.ncbi.nlm.nih.gov/pubmed/9715971 (accessed on 25 April 2018). [PubMed]

28. Ventura, N.; Hoppeler, H.; Seiler, R.; Binggeli, A.; Mullis, P.; Vogt, M. The Response of Trained Athletes to Six Weeks of Endurance Training in Hypoxia or Normoxia. Int. J. Sports Med. 2003, 24, 166-172. [CrossRef]

29. Spencer, M.; Bishop, D.; Dawson, B.; Goodman, C. Physiological and Metabolic Responses of Repeated-Sprint Activities. Sport Med. 2005, 35, 1025-1044. [CrossRef]

30. Keskinen, O.P.; Keskinen, K.L.; Mero, A.A. Effect of pool length on blood lactate, heart rate, and velocity in swimming. Int. J. Sports Med. 2007, 28, 407-413. [CrossRef]

31. Girard, O.; Billaut, F.; Christian, R.J.; Bradley, P.S.; Bishop, D.J. Exercise-related sensations contribute to decrease power during repeated cycle sprints with limited influence on neural drive. Eur. J. Appl. Physiol. 2017, 117, 2171-2179. [CrossRef]

32. Hamlin, M.J.; Lizamore, C.A.; Hopkins, W.G. The Effect of Natural or Simulated Altitude Training on High-Intensity Intermittent Running Performance in Team-Sport Athletes: A Meta-Analysis. Sport Med. 2017, 46, 431-446. [CrossRef]

33. Stringer, W.; Wasserman, K.; Casaburi, R.; Porszasa, J.; Maehara, K.; French, W. Lactic acidosis as a facilitator of oxyhemoglobin dissociation during exercise. J. Appl. Physiol. 1994, 76. Available online: https://www.physiology.org/doi/pdf/10.1152/jappl.19 94.76.4.1462 (accessed on 30 April 2018).

34. Sutton, J.R.; Reeves, J.T.; Wagner, P.D.; Groves, B.M.; Cymerman, A.L.L.E.N.; Malconian, M.K.; Rock, P.B.; Young, P.M.; Walter, S.D.; Houston, C.S. Operation Everest II: Oxygen transport during exercise at extreme simulated altitude. J. Appl. Physiol. 1988, 64, 1309-1321. [CrossRef] [PubMed]

35. Meert, K.L.; Clark, J.; Sarnaik, A.P. Metabolic acidosis as an underlying mechanism of respiratory distress in children with severe acute asthma. Pediatr. Crit. Care Med. 2007, 8, 519-523. [CrossRef] [PubMed]

36. Meyer, T.; Faude, O.; Scharhag, J.; Urhausen, A.; Kindermann, W. Is lactic acidosis a cause of exercise induced hyperventilation at the respiratory compensation point? Br. J. Sports Med. 2004, 38, 622-625. [CrossRef] [PubMed]

37. Creer, A.R.; Ricard, M.D.; Conlee, R.K.; Hoyt, G.L.; Parcell, A.C. Neural, Metabolic, and Performance Adaptations to Four Weeks of High Intensity Sprint-Interval Training in Trained Cyclists. Int. J. Sports Med. 2004, 25, 92-98. [CrossRef] [PubMed]

38. Strass, D. Effects of Maximal Strength Training on Sprint Performance of Competitive Swimmers. Int. Ser. Sport Sci. 1988, 18, 149-156.

39. Myer, G.D.; Ford, K.R.; Palumbo, J.P.; Hewett, T.E. Neuromuscular training improves performance and lower-extremity biomechanics in female athletes. J. Strength Cond. Res. 2005, 19, 51-60. [CrossRef] [PubMed]

40. Ross, A.; Leveritt, M.; Riek, S. Neural Influences on Sprint Running. Sport Med. 2001, 31, 409-425. [CrossRef]

41. Mendez-Villanueva, A.; Hamer, P.; Bishop, D. Fatigue in repeated-sprint exercise is related to muscle power factors and reduced neuromuscular activity. Eur. J. Appl. Physiol. 2008, 103, 411-419. [CrossRef] 
42. Dietz, V.; Schmidtbleicher, D.; Noth, J. Neuronal Mechanisms of Human Locomotion. J. Neurophysiol. 1979, 42, 1212-1222. Available online: https:/ / www.physiology.org/doi/pdf/10.1152/jn.1979.42.5.1212 (accessed on 24 April 2018). [CrossRef]

43. Amann, M.; Eldridge, M.W.; Lovering, A.T.; Stickland, M.K.; Pegelow, D.F.; Dempsey, J.A. Arterial oxygenation influences central motor output and exercise performance via effects on peripheral locomotor muscle fatigue in humans. J. Physiol. 2006, 575, 937-952. [CrossRef] [PubMed]

44. Truijens, M.J.; Toussaint, H.M.; Dow, J.; Levine, B.D. Effect of high-intensity hypoxic training on sea-level swimming performances. J. Appl. Physiol. 2003, 94, 733-743. [CrossRef] [PubMed]

45. Cometti, G.; Maffiuletti, N.; Pousson, M.; Chatard, J.; Maffulli, N. Isokinetic strength and anaerobic power of elite, subelite, and amateur french soccer players. Int. J. Sports Med. 2001, 22, 45-51. [CrossRef] [PubMed]

46. Gabbett, T.; Kelly, J.; Ralph, S.; Driscoll, D. Physiological and anthropometric characteristics of junior elite and sub-elite rugby league players, with special reference to starters and non-starters. J. Sci. Med. Sport 2009, 12, 215-222. [CrossRef]

47. Andreacci, J.L.; Lemura, L.M.; Cohen, S.L.; Urbansky, E.A.; Chelland, S.A.; von Duvillard, S.P. The effects of frequency of encouragement on performance during maximal exercise testing. J. Sports Sci. 2002, 20, 345-352. [CrossRef] 